\title{
Impact of Internal Migration on Children in China: Inequality of educational opportunities
}

\author{
Abstract ID: 57 - Monday, 15th September 16.00 - Room 232 - Oral
}

Xiaoyue Sun*, Mengtong Chen, Edward Chan (The University of Hong Kong)

\section{Objectives}

There were 38.81 million children migrated from rural areas to urban areas in mainland China according to data from China's 2010 Census. However, the unequal opportunities to education for migrant children negatively impact their development. In regard to the lack of quantitative synthesis of education opportunity of migrant children, we undertook a meta-analysis approach to examine school attendance rates of migrant children in urban areas of China.

\section{Method}

Using meta-regression methodology, nine studies were selected from 1387 studies for analysis. First, school attendance rates of all sampled students were synthesized with Comprehensive Meta Analysis (CMA). Second, school attendance rates of migrant children were compared by geographical regions: eastern, central and western areas of Mainland China.

\section{Results}

The school attendance rate of migrant children across the country was $63.6 \%$, which was significantly lower than the rate for general population that was almost $100 \%$. Regional differences in public school attendance rates showed that the western region had the highest rate at $97.4 \%$, the central region had $64.6 \%$, while the eastern region had the lowest rate at $55.5 \%$. Local policies, school characteristics and household background determined the school attendance status and school selection of migrant children.

\section{Conclusion}

Migrant children were disadvantaged in compulsory education, as only $84.6 \%$ of them were attending school, compared to virtually $100 \%$ of non-migrant children in cities. That disparity indicated educational opportunity inequality between local children and migrant children. When it comes to migrant children's attendance in public schools, the attendance rate was even lower, so a significant portion of them had to attend low-quality schools exclusively for migrant children. Last but not least, the difference of attendance rates among eastern coastal, central and western regions was significant, showing that migrant children in eastern region had less opportunities of enrolling in government-sponsored schools compared to others. 